\section{Dates for your}

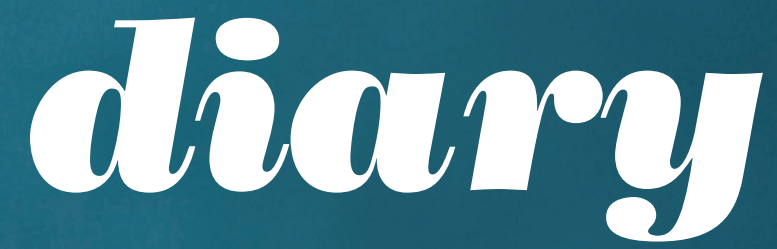

If you have an event you want featured in 2019, email the Editor: caroline.holland@nature.com

The Orthodontic National Group Spring Study Day March 2, Birmingham, RCS (Ed) Regional Centre, 85-89 Colmore Row, B3 2BB

9am-4pm, 5 hours verifiable CPD

Speakers include Marwa Maarouf, George Jones, Sheena

Kotecha and Jane Bonehill.

Facebook.com/orthodonticnationalgroup or wwW.

orthodontic-ong.org

\section{The ADI Team Congress 2019}

Mav 2-4 the Edinburgh Internotional Conference Centre (EICC)

The Future of Dental Implantology: TechniquesTechnology - Teamwork.

An event for experienced dental professionals as well as those who have just started out with dental implants, the Congress gives the chance to gain up-to-date knowledge, make new discoveries, network with like-minded individuals and make new contacts. The event will see a major trade exhibition hosting a wide selection of stands where professionals can experience new products and discover the latest advancements. For more information, please visit www.adi.org.uk

https://www.adi.org.uk/events/events.php

\section{National Orthodontic Therapist Day}

Speakers: David Waring, Steve Chadwick, Simon Littlewood, Amy Gallacher, Richard Needham, Badri Thiruvenkatachari, Ovais Malik.

Limited spaces, book early: www.bos.org.uk

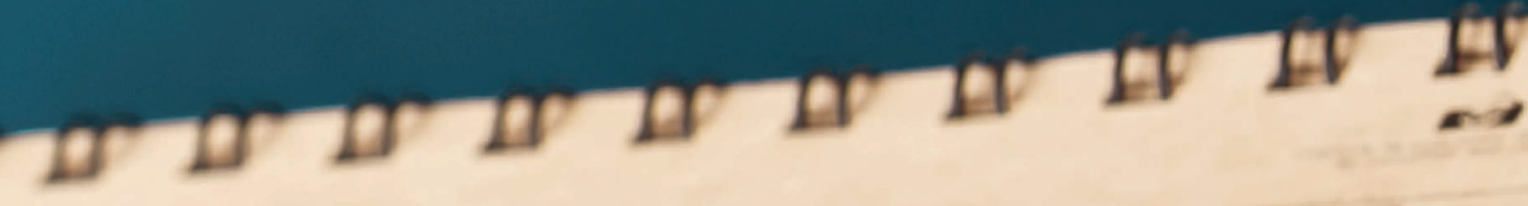

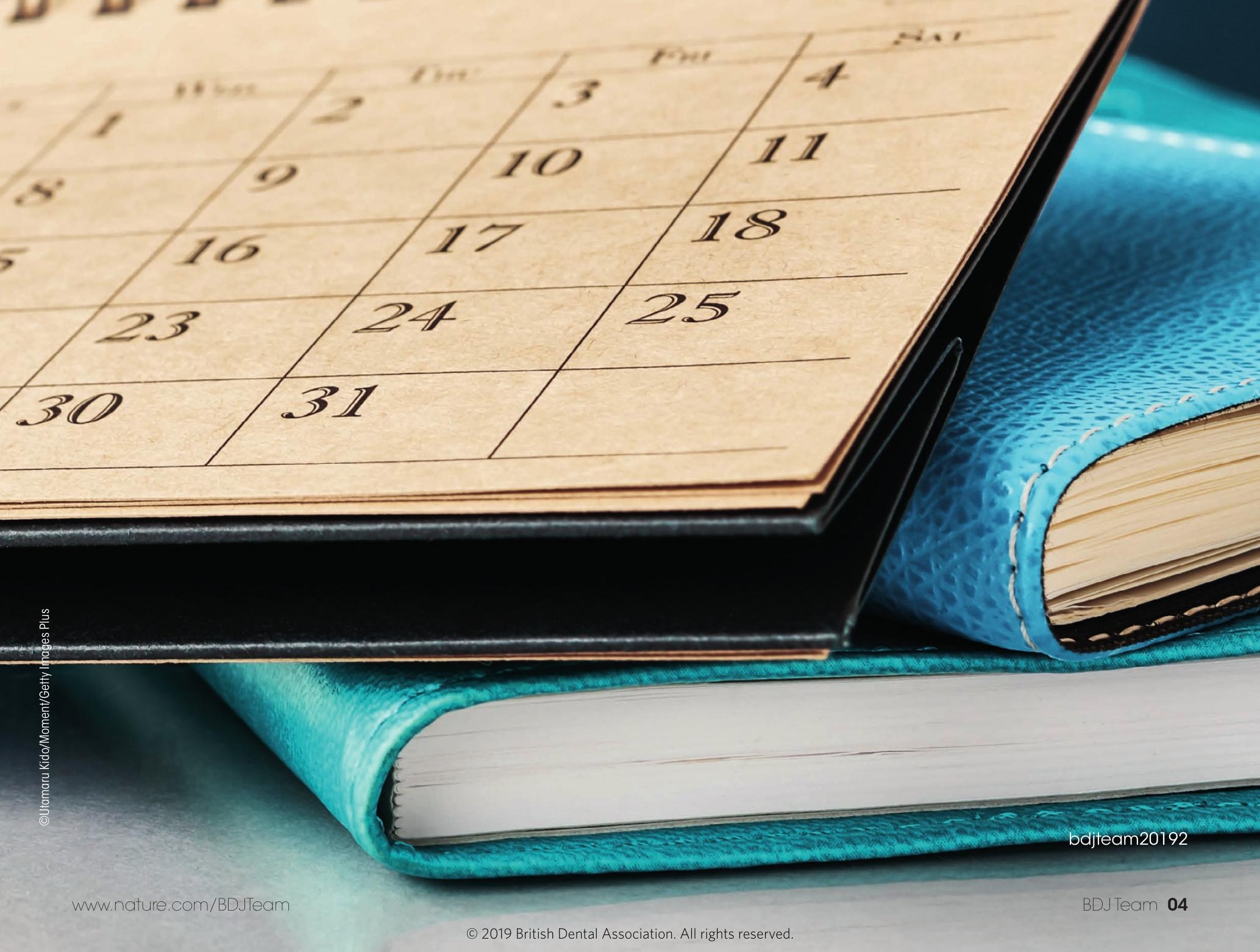

